\title{
Retrospective Description of Pregnant Women Infected with Severe Acute Respiratory Syndrome Coronavirus 2, France
}

\author{
Alexandre J. Vivanti, Jérémie Mattern, Christelle Vauloup-Fellous, Jacques Jani, \\ Luc Rigonnot, Larissa El Hachem, Agnès Le Gouez, Céline Desconclois, Imane Ben M'Barek, \\ Jeanne Sibiude, Alexandra Benachi, Olivier Picone, Anne-Gaël Cordier
}

Few data are available on the management of pregnant women infected with severe acute respiratory syndrome coronavirus 2 (SARS-CoV-2). We conducted a retrospective study of 100 pregnant women with SARS-CoV-2 infection in 4 obstetric units in the Paris metropolitan area of France during March 12-April 13, 2020. Among patients, 52 (52\%) were hospitalized, 10 $(10 \%)$ in intensive care units (ICUs). Women with higher body mass indexes (BMls; median $30.7 \mathrm{~kg} / \mathrm{m}^{2}$ ) were more likely to be hospitalized in ICUs than other women (median BMI $26.2 \mathrm{~kg} / \mathrm{m}^{2}$ ). Women hospitalized in ICUs had lower lymphocyte count at diagnosis (median 0.77 $\times 10^{9} \mathrm{cells} / \mathrm{L}$ ) than women not hospitalized in ICUs (median lymphocyte count $1.15 \times 10^{9}$ cells/L). All women requiring oxygen $>5 \mathrm{~L} / \mathrm{min}$ were intubated. Clinical and laboratory evaluation of SARS-CoV-2-positive pregnant women at the time of diagnosis can identify patients at risk for ICU hospitalization.

$\mathrm{R}$ ecent literature from China, Italy, and the United States suggests that pregnant women are not at higher risk for severe forms of coronavirus disease (COVID-19) from infection with severe acute respiratory syndrome (SARS) coronavirus 2 (SARS-CoV-2),

Author affiliations: Antoine Béclère Hospital, Paris Saclay University, Clamart, France (A.J. Vivanti, J. Mattern, A. Le Gouez, C. Desconclois, A. Benachi); Paul Brousse Hospital, Paris Saclay University, Villejuif, France (C. Vauloup-Fellous); University Hospital Brugmann, Université Libre de Bruxelles, Brussels, Belgium (J. Jani); Centre Hospitalier Sud-Francilien, Corbeil-Essonnes, France (L. Rigonnot, L. El Hachem); Bicêtre Hospital, Paris Saclay University, Le Kremlin-Bicêtre, France (I. Ben M'Barek, A.-G. Cordier); Louis Mourier Hospital, Paris University, Colombes, France (J. Sibiude, O. Picone)

DOI: https://doi.org/10.3201/eid2609.202144 contrary to what has been reported with SARS and MERS (1-3). Nevertheless, 3\%-35\% of infected pregnant women were hospitalized in intensive care units (ICUs) $(2,4-7)$ and respiratory and hematology anomalies were described, just as in the nonpregnant infected population (8). In the third trimester, and especially after 37 weeks' gestation, the fetal prognosis is driven by maternal clinical tolerance and by whether a cesarean delivery is required. Few cases of vertical transmission have been published (6-9), and no data are available on the risk factors for such transmission. However, between 24 and 32 weeks' gestation, the risk for premature birth and the need to reduce its effects on neonatal outcome by giving steroids and magnesium sulfate to the mother complicate decision-making. Little published data are available on the management of SARS-CoV-2-infected pregnant women (10). We describe the experience of 4 tertiary referral obstetric units in managing such cases in the Paris metropolitan area of France.

\section{Materials and Methods}

\section{Study Design and Population}

We conducted a retrospective multicenter review of the medical records of all pregnant women with SARS-CoV-2 from March 12-April 13, 2020, in 4 tertiary referral obstetric units in the Paris metropolitan area. Hospitals included in the study were Antoine Béclère, Clamart; Bicêtre Hospital, Le Kremlin Bicêtre; Louis-Mourier, Colombes; and Centre Hospitalier Sud Francilien, Evry. All women in the second and third trimester of pregnancy $(\geq 14$ weeks' gestation) had real-time reverse transcription PCR (RTPCR) testing of respiratory tract samples to detect 
SARS-CoV-2. Gestational age was calculated according to crown-rump length measurement at the first-trimester scan. Because of the moderate sensitivity of RT-PCR (11-13), patients with negative results also had computed tomography imaging of the chest, which was considered positive when meeting conventional criteria for SARS-CoV-2 infection (14). Patients were considered cured $\geq 10$ days after the positive diagnosis and without clinical signs for 48 $\mathrm{h}$, or 14 days from the beginning of the disease with only benign signs without hospitalization.

We retrospectively allocated women to subgroups according to location for further care after first assessment. The outpatient follow-up group was defined as infected pregnant women who could return home after assessment in the emergency department. Close outpatient follow-up was undertaken and included a daily call from an obstetrician/gynecologist. In the case of suspected worsening, such as fever, dyspnea, or tachycardia, or obstetric concern, women were asked to return to the hospital for further assessment and hospitalized, if needed. The conventional hospitalization group was defined as women immediately hospitalized after SARS-CoV-2 diagnosis because close medical supervision or noninvasive oxygen therapy with flow rates $<3 \mathrm{~L} / \mathrm{min}$, was needed. The ICU hospitalization group was defined as women hospitalized in ICUs because of clinical worsening, including respiratory distress or increased

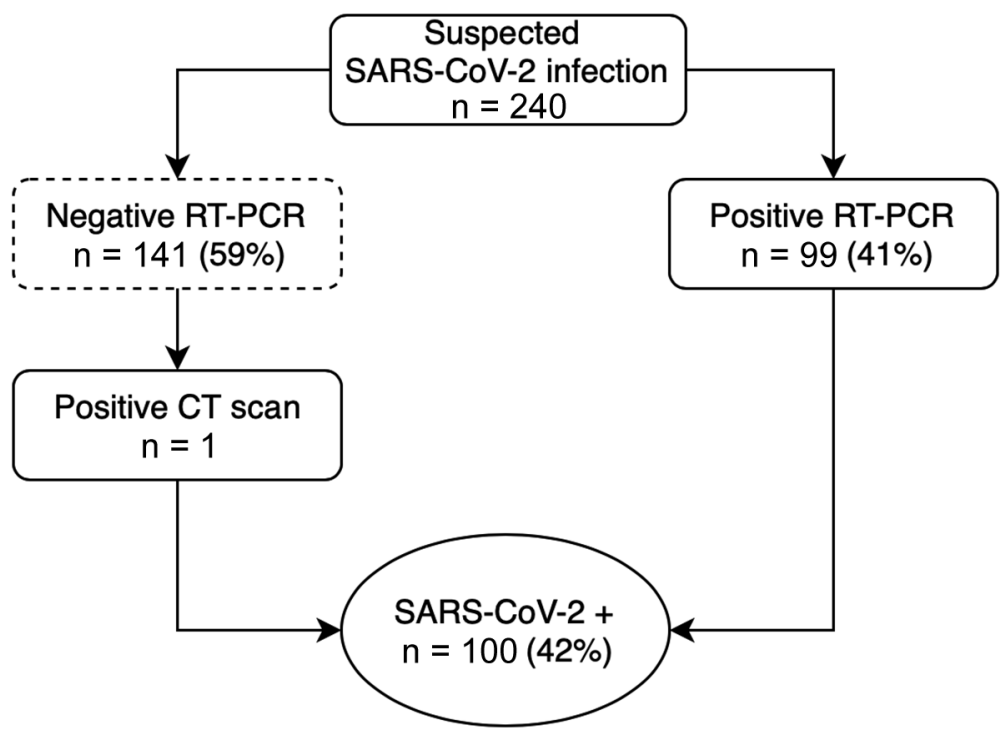

Figure. Flowchart of study data showing status and medical referral in a cohort of pregnant women with SARS-CoV-2 infection, France. CT, computed tomography; RT-PCR, reverse transcription PCR; SARS-

CoV-2, severe acute respiratory syndrome coronavirus 2 .

\section{First medical referral}

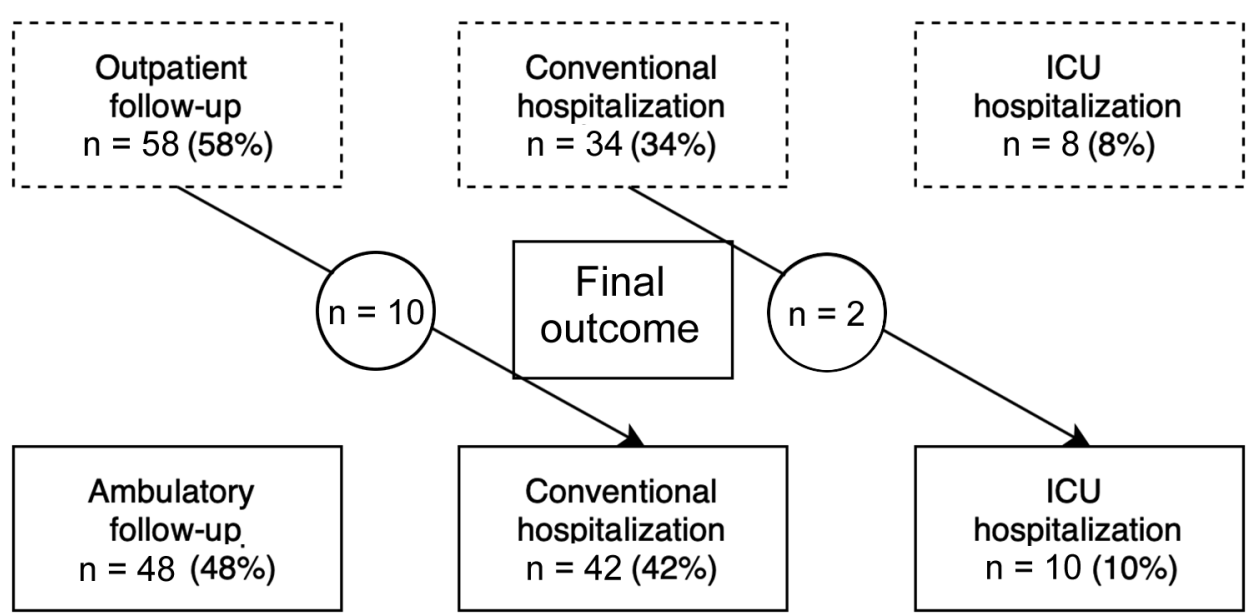


oxygen requirement, and the need for continuous medical supervision, noninvasive high-flow oxygen delivery, or invasive mechanical ventilation.

\section{Sample Collection}

Laboratory samples were obtained for RT-PCR and prepared as follows. Nasopharyngeal swabs were obtained following US Centers for Disease Control and Prevention guidelines (15). Swabs were placed in Virocult viral transport media (Sigma, https:/ / www. sigmaaldrich.com). All specimens were kept at $4^{\circ} \mathrm{C}$ and tested within 24 hours.

\section{RT-PCR}

Viral RNA was extracted from $200 \mu \mathrm{L}$ of clinical samples with the NucliSENS easyMag kit (BioMérieux, https:/ / www.biomerieux.com) and eluted in $100 \mu \mathrm{L}$. The RealStar SARS-CoV-2 RT-PCR Kit 1.0 (Altona Diagnostics $\mathrm{GmbH}$, https://www.altona-diagnostics.com) targeting the E gene, specific for lineage Bbetacoronavirus, and the $\mathrm{S}$ gene, specific for SARS$\mathrm{CoV}-2$, was used, according to the manufacturer's recommendations. The assay includes a heterologous amplification system as an internal positive control to identify possible RT-PCR inhibition and to confirm the integrity of the reagents of the kit. Thermal cycling was performed at $55^{\circ} \mathrm{C}$ for $20 \mathrm{~min}$ for reverse

\begin{tabular}{lc}
\hline \multicolumn{2}{l}{ Table 1. Baseline characteristics at diagnosis for pregnant } \\
women infected with sever acute respiratory syndrome 2, \\
France* \\
\hline Maternal and obstetric characteristics & Value \\
\hline Total patients & 100 \\
\hline Median age, y (IQR) & $33.7(29-36.7)$ \\
Median gravidity (IQR) & $3(1.8-4)$ \\
Median parity (IQR) & $1(0-3)$ \\
Median BMI, kg/m² (IQR) & $27.0(23.5-30.6)$ \\
\hline Preexisting conditions & $7(7)$ \\
Diabetes mellitus & $6(6)$ \\
Chronic high blood pressure & $2(2)$ \\
Tobacco use & $9(9)$ \\
Asthma & $(25.6-35.6)$ \\
\hline Median gestational age at diagnosis, wk (IQR) & $18(18)$ \\
14-24 & $41(41)$ \\
$25-32$ & $20(20)$ \\
$33-37$ & $20(20)$ \\
$>37$ & $1(1)$ \\
Early postpartum & \\
\hline Signs and symptoms & $62(62)$ \\
Fever & $80(80)$ \\
Cough & $30(30)$ \\
Dyspnea & $26(26)$ \\
Myalgia & $16(16)$ \\
Anosmia & $9(9)$ \\
Sore throat & $10(10)$ \\
Diarrhea or vomiting & 0 \\
Rash & $13(13)$ \\
Other signs & \\
*Values are no. (\%) except as indicated. BMI, body mass index; IQR, \\
interquartile range.
\end{tabular}

transcription, followed by $95^{\circ} \mathrm{C}$ for $2 \mathrm{~min}$, and then 45 cycles of $95^{\circ} \mathrm{C}$ for $15 \mathrm{~s}, 55^{\circ} \mathrm{C}$ for $45 \mathrm{~s}$, and $72^{\circ} \mathrm{C}$ for $15 \mathrm{~s}$ with an Applied Biosystems ViiA7 instrument (ThermoFisher Scientific, https://www.thermofisher. com). A cycle threshold $<40$ was considered positive for SARS-CoV-2 RNA.

\section{Data Collection and Statistical Analysis}

We retrospectively collected clinical, laboratory, and imaging data on mothers and newborns from medical records. We performed statistical analyses by using GraphPad Prism version 8.0.0 (GraphPad Software, https:/ / www.graphpad.com). We used a 2-tailed Mann-Whitney U test for statistical analysis of continuous variables and Fisher exact test for statistical analysis of categorical variables. We expressed continuous variables as median with interquartile range (IQR) and categorical variables as number (percentage). We considered $p<0.05$ statistically significant.

This study was approved by the institutional review board of the French College of Obstetricians and Gynecologists (approval no. CEROG OBS-20200402). All data were de-identified to ensure patient privacy and confidentiality.

\section{Results}

\section{Maternal Characteristics and Signs and Symptoms at Diagnosis}

During March 12-April 13, 2020, a total of 240 women were tested for SARS-CoV-2 infection during pregnancy or the early postpartum period because of relevant symptoms (Figure). Among them, 100 (42\%) were considered infected; $99(41 \%)$ had a positive RT-PCR, and 1 woman with a negative RT-PCR test was considered positive because computed tomography imaging of the chest was compatible with SARS-CoV-2 infection. The median age of the infected women was 33.7 years (range 29-36.7 years); 81 $(81 \%)$ were tested after 24 weeks' gestation, and 18 (18\%) were tested between 14 and 24 weeks' gestation. One asymptomatic patient was tested 2 days postpartum because of an isolated increase in activated partial thromboplastin time (aPPT; ratio 1.40), but signs of primary coagulopathy or consumption were not noted, and the patient's platelet count was $154 \times 10^{9} / \mathrm{L}$, prothrombin time ratio was $100 \%$, and fibrinogen activity was $5.5 \mathrm{~g} / \mathrm{L}$.

A few patients had underlying conditions, including $9(9 \%)$ with asthma, $7(7 \%)$ with diabetes mellitus, and $6(6 \%)$ with chronic high blood pressure. Median body mass index (BMI) was $27.0 \mathrm{~kg} / \mathrm{m}^{2}$ 
Table 2. Maternal and obstetric characteristics according to medical referral for pregnant women with severe acute respiratory syndrome 2 infection, France*

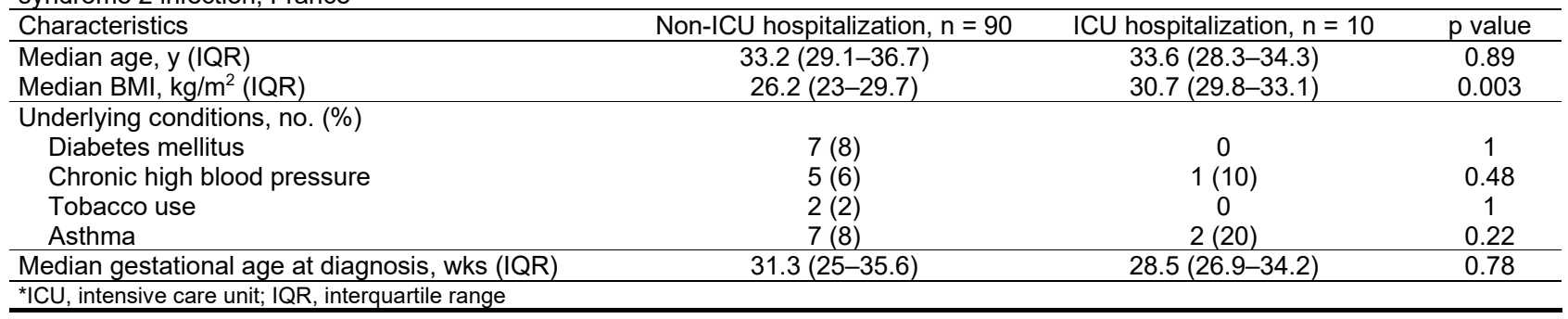

(IQR $\left.23.5-30.6 \mathrm{~kg} / \mathrm{m}^{2}\right)$. At diagnosis, all but 1 woman experienced symptoms compatible with SARS-CoV-2 infection; 80 (80\%) had cough, $62(62 \%)$ had fever, 30 (30\%) had dyspnea, $26(26 \%)$ had myalgia, $16(16 \%)$ had anosmia, and $10(10 \%)$ had gastrointestinal symptoms. None reported rash (Table 1).

After a first evaluation, 58 (58\%) of the infected women were eligible for close outpatient followup; 10 (17\%) were hospitalized during later followup. Forty-two (42\%) women were immediately hospitalized, $8(19 \%)$ in ICUs and $34(80.9 \%)$ in conventional wards. Later, 2 women were switched from conventional hospitalization to the ICU because of increased respiratory symptoms. Among all patients, $32(32 \%)$ required oxygen therapy. At the end of the study period, $48(48 \%)$ patients received outpatient follow-up only, and 52 (52\%) were hospitalized, 42 in conventional wards and 10 in ICUs.

We found that women with a high BMI (30.7 $\mathrm{kg} / \mathrm{m}^{2}$ [IQR $29.8-33.1 \mathrm{~kg} / \mathrm{m}^{2}$ ]) were more likely to be hospitalized in ICUs than women with lower BMIs $\left(26.2 \mathrm{~kg} / \mathrm{m}^{2}\right.$ [IQR $\left.\left.23-29.7 \mathrm{~kg} / \mathrm{m}^{2}\right] ; \mathrm{p}=0.003\right)$. We noted no statistically significant difference in maternal age, gravidity, parity, gestational age at diagnosis, or preexisting medical conditions among patients admitted to ICUs (Table 2). We performed a similar comparison between women with outpatient follow-up (BMI $26.2 \mathrm{~kg} / \mathrm{m}^{2}$ [IQR 22.9-29.9 kg/m²]) and women who required hospitalization (BMI 30.7 $\mathrm{kg} / \mathrm{m}^{2}$ [IQR $\left.24.5-30.9 \mathrm{~kg} / \mathrm{m}^{2}\right]$ ). We noted BMI also was the only maternal baseline characteristic with a statistically significant difference $(p=0.003)$ between the 2 groups (Appendix Table 1, https:/ / wwnc.cdc. gov/EID/article/26/9/20-2144-App1.pdf). No maternal thromboembolic event was noted during the study period.

\section{Laboratory Parameters at SARS-CoV-2 Diagnosis}

We analyzed laboratory parameters at diagnosis for maternal medical care (Table 3). Lymphocyte count at diagnosis was lower in women hospitalized in ICUs $\left(0.77 \times 10^{9}\right.$ cells/L [IQR $0.7-1 \times 10^{9}$ cells/L] $)$ than in women in the conventional hospitalization or outpatient follow-up groups $\left(1.15 \times 10^{9}\right.$ cells/L [IQR 0.9-1.6 $\times 10^{9}$ cells $\left.\left./ \mathrm{L}\right] ; \mathrm{p}=0.01\right)$. Moreover, the proportion of women with lymphocytopenia at diagnosis also was much higher in the ICU group $(89 \%)$ than in the rest of the cohort $(36 \% ; p=0.008)$. Hemoglobin count at diagnosis was lower in women who needed hospitalization in ICUs $(9.8 \mathrm{~g} / \mathrm{dL}[\mathrm{IQR}$ 9.3-11.3 g/dL]) than in the rest of the cohort $(11.4 \mathrm{~g} /$

Table 3. Laboratory parameters at diagnosis according to medical referral for pregnant women with severe acute respiratory syndrome 2 infection, France*

\begin{tabular}{|c|c|c|c|c|c|}
\hline \multirow[b]{2}{*}{ Laboratory findings } & \multicolumn{2}{|c|}{ Non-ICU hospitalization, $\mathrm{n}=90$} & \multicolumn{2}{|c|}{ ICU hospitalization, $n=10$} & \multirow[b]{2}{*}{$p$ value } \\
\hline & Median (IQR) & No. $(\%)$ & Median (IQR) & No. $(\%)$ & \\
\hline Hemoglobin, g/dL & $11.4(10.5-12.2)$ & $64(66.7)$ & $9.8(9.3-11.3)$ & $9(90)$ & 0.02 \\
\hline Platelet count, $\times 10^{9} / \mathrm{L}$ & $230(162-273)$ & $63(70.0)$ & $205(164-271)$ & $9(90)$ & 0.98 \\
\hline Leukocyte count, $\times 10^{9}$ cells $/ \mathrm{L}$ & $7.2(5.4-8.9)$ & $63(70.0)$ & $6.6(6.1-7.2)$ & $9(90)$ & 0.68 \\
\hline Lymphocyte count, $\times 10^{9} \mathrm{cells} / \mathrm{L}$ & $1.15(0.9-1.6)$ & $58(64.4)$ & $0.77(0.7-1)$ & $9(90)$ & 0.01 \\
\hline Lymphocytopenia, $<1.00 \times 10^{9}$ cells $/ \mathrm{L}$ & NA & $21 / 58(36.2) \dagger$ & NA & 8/9 (88.9)† & 0.008 \\
\hline Prothrombin time, $\%$ & $100(99-100)$ & $53(58.9)$ & $100(100-100)$ & $7(70)$ & 0.61 \\
\hline aPPT, ratio & $1.06(1-1.2)$ & $52(57.8)$ & $1.12(1-1.4)$ & 7 (70) & 0.16 \\
\hline Prolonged aPPT ratio $(\geq 1.20)$ & NA & $13 / 53(24.5) \dagger$ & NA & 3/7 (43)† & 0.38 \\
\hline Fibrinogen activity, $\mathrm{g} / \mathrm{L}$ & $4.8(4-5.8)$ & $45(50.0)$ & $5.1(4.5-5.5)$ & $6(60)$ & 0.73 \\
\hline AST, U/L & $25(20-35)$ & $48(53.3)$ & $30(22-59)$ & $8(80)$ & 0.38 \\
\hline $\mathrm{ALT}, \mathrm{U} / \mathrm{L}$ & $17(11-32)$ & $49(54.4)$ & $19(12-48)$ & $8(80)$ & 0.46 \\
\hline C-reactive protein, $\mathrm{mg} / \mathrm{L}$ & $23(9-42)$ & $53(58.9)$ & $27(22-108)$ & $8(80)$ & 0.15 \\
\hline Creatinine, $\mu \mathrm{mol} / \mathrm{L}$ & $47(41-57)$ & $45(50.0)$ & $50(38-55)$ & $7(70)$ & 0.94 \\
\hline
\end{tabular}


Pregnant Women Infected with SARS-CoV-2, France

$\mathrm{dL}$ [IQR 10.5-12.2 g/dL]; $\mathrm{p}=0.02)$. We did not detect any statistically significant differences between the 3 groups for white cell count, prothrombin time, aPPT, fibrinogen activity, alanine aminotransferase, aspartate aminotransferase, C-reactive protein, or creatinine. We performed a similar comparison between women with outpatient follow-up and women who required hospitalization and found no statistically significant between-group differences in any laboratory parameter (Appendix Table 2). We assessed laboratory parameters at diagnosis and oxygen therapy requirements and noted that women with lymphocytopenia and prolonged aPPT at diagnosis were more likely to need an oxygen therapy (Appendix Table 3). Similarly, we noted lower lymphocyte counts, increased aPPT ratios, and increased C-reactive protein levels for women who required oxygen therapy than for the others.

\begin{tabular}{|c|c|}
\hline Obstetric outcomes & Value \\
\hline Ongoing pregnancies & $67(67.0)$ \\
\hline Stillbirths or miscarriages & 0 \\
\hline Deliveries & $33(33.0)$ \\
\hline $\begin{array}{l}\text { Median days between SARS-CoV-2 } \\
\text { diagnosis and delivery (IQR) }\end{array}$ & $3(1-9)$ \\
\hline \multicolumn{2}{|l|}{ Delivery mode } \\
\hline Vaginal & $17(51.5)$ \\
\hline Spontaneous labor & $9(52.9)$ \\
\hline Induced labor, reason & $8(47.1)$ \\
\hline Respiratory degradation & $4(50.0)$ \\
\hline Preeclampsia & $1(12.5)$ \\
\hline Intrahepatic cholestasis & $1(12.5)$ \\
\hline Reduced fetal movements & $1(12.5)$ \\
\hline Premature rupture of membranes & $1(12.5)$ \\
\hline Caesarean delivery, reason & $16(48.5)$ \\
\hline Respiratory distress & $12(36.4)$ \\
\hline Major coagulopathy & $1(6.3)$ \\
\hline Severe preeclampsia & $1(6.3)$ \\
\hline Non-reassuring fetal heart rate & $1(6.3)$ \\
\hline Definitive cervicoisthmic cerclage & $1(6.3)$ \\
\hline Gestational age at birth, wk, median (IQR) & $37.9(35-40.1)$ \\
\hline$\geq 37$ & $20(60.6)$ \\
\hline $32-36$ & $13(39.4)$ \\
\hline $24-31$ & $7(21.2)$ \\
\hline Twin pregnancies & $3(3.0)$ \\
\hline Neonatest & 36 \\
\hline Birthweight z-score, g, median (IQR) & $0.15(-0.75$ to 0.64$)$ \\
\hline$<10$ th percentile & $1(3)$ \\
\hline \multicolumn{2}{|l|}{ Apgar score $<7$} \\
\hline $1 \mathrm{~min}$ & $8(22)$ \\
\hline $5 \mathrm{~min}$ & $4(11)$ \\
\hline $10 \mathrm{~min}$ & $1(3)$ \\
\hline Umbilical arterial $\mathrm{pH}$, median (IQR) & $7.26(7.24-7.29)$ \\
\hline Neonatal intubation & $6(17)$ \\
\hline NICU hospitalization & $10(28)$ \\
\hline Neonatal death & 0 \\
\hline Neonate SARS-CoV-2-positive & $1(3)$ \\
\hline
\end{tabular}

\section{Obstetric and Neonatal Outcomes}

At the end of the study period, 33 women (33\%) had delivered 36 neonates, including 3 twin deliveries. Median gestational age of neonates was 37.9 weeks (IQR 35-40.1 weeks) (Table 4). Deliveries in SARSCoV-2-infected women represented $2.4 \%$ of the 1,362 deliveries in the 4 hospitals. Preterm births, those at $<37$ weeks' gestation, represented 39\% of the whole cohort; the median interval between SARS-CoV-2 diagnosis and delivery was 3 days (IQR 1-9 days). No stillbirths or miscarriages occurred among the study population. Among deliveries, 16 (48\%) were cesarean deliveries, $13(36 \%)$ of which were because of SARS-CoV-2 infection, 12 because of maternal respiratory distress, and 1 because of major coagulopathy. All women who delivered before 32 weeks' gestation were given antenatal magnesium sulfate therapy. All but 1 of the women who delivered before 34 weeks' gestation were given antenatal corticosteroid therapy (2 doses of betamethasone $12 \mathrm{mg}$ given intramuscularly 24 hours apart).

Only 1 neonate had a birthweight below the 10th percentile; 10 were hospitalized in the neonatal ICU (NICU) because of prematurity. No neonatal acidosis was noted; median umbilical arterial $\mathrm{pH}$ was 7.26 (IQR 7.24-7.29), even for most severe maternal cases.

All the neonates were tested for SARS-CoV-2 infection. Only 1 neonate tested positive for SARSCoV-2; his mother had no severe clinical symptoms but experienced cough and fever at 35 weeks' gestation. At admission, her laboratory workup showed mild thrombocytopenia and prolonged aPPT. Her symptoms improved rapidly during early postpartum. The infant did not require oxygen, but results of RT-PCR testing on nasopharyngeal secretions were positive. He did not show signs of respiratory illness.

Among 3 twin pregnancies, the mother's SARSCoV-2 diagnosis was made between 31.4 and 35.4 weeks' gestation; 1 of the mothers was severely obese $\left(\right.$ BMI $\left.49 \mathrm{~kg} / \mathrm{m}^{2}\right)$. At the time of diagnosis, 1 patient had severe lymphocytopenia $\left(0.35 \times 10^{9}\right.$ cells/L) and another had prolonged aPTT (ratio 1.22). Two women were hospitalized because of dyspnea; both had cesarean deliveries, at 31.7 and 35.4 weeks' gestation, due to increased respiratory complications, but neither was admitted to the ICU. The third had a vaginal delivery at 37 weeks' gestation. One pair of twins was hospitalized in the NICU because of prematurity. Neonatal acidosis was not observed in any cases.

\section{Pregnant Women in ICUs}

At the end of the study period, $10(10 \%)$ patients had been admitted to ICUs: 7 during prenatal period 
Table 5. Maternal outcomes of 10 pregnant women admitted to the intensive unit with severe acute respiratory syndrome coronavirus 2, France*

\begin{tabular}{|c|c|c|c|c|c|c|c|c|c|c|c|}
\hline \multirow[b]{3}{*}{ ID } & \multirow[b]{3}{*}{ Age, y } & \multirow[b]{3}{*}{$\begin{array}{l}\mathrm{BMI} \\
\mathrm{kg} / \mathrm{m}^{2}\end{array}$} & \multirow[b]{3}{*}{$\begin{array}{l}\text { Underlying } \\
\text { conditions }\end{array}$} & & & \multicolumn{2}{|c|}{ Time, $\mathrm{h}$} & \multirow[b]{3}{*}{$\begin{array}{c}\text { Intubation, } \\
\text { d }\end{array}$} & \multirow[b]{3}{*}{$\begin{array}{l}\text { ICU } \\
\text { stay, d }\end{array}$} & \multirow[b]{3}{*}{$\begin{array}{l}\text { Drug } \\
\text { regimens }\end{array}$} & \multirow[b]{3}{*}{ Complications } \\
\hline & & & & \multicolumn{2}{|c|}{ GA, wk, d } & From $\mathrm{O}_{2}>5$ & From & & & & \\
\hline & & & & $\begin{array}{c}\text { At } \\
\text { diagnosis }\end{array}$ & $\begin{array}{c}\text { At } \\
\text { intubation }\end{array}$ & $\begin{array}{l}\mathrm{L} / \mathrm{min} \text { to } \\
\text { intubation }\end{array}$ & $\begin{array}{l}\text { intubation } \\
\text { to delivery }\end{array}$ & & & & \\
\hline 1 & $30.9 \dagger$ & 35.8 & NA & 28,5 & 29,0 & 15.5 & 0 & 10 & 12 & Lopinavir & NA \\
\hline 2 & $26.5 \dagger$ & 29.9 & NA & 38,1 & POD 2 & 7 & NA & 15 & 16 & Hydroxy & $\begin{array}{l}\text { Surgical site } \\
\text { infection }\end{array}$ \\
\hline 3 & $24.9 \dagger$ & 25.7 & Asthma & 28,5 & 30,1 & 10 & 0 & 11 & 13 & Lopinavir & $\begin{array}{l}\text { latrogenic } \\
\text { pancreatitis }\end{array}$ \\
\hline 4 & $32.6 \dagger$ & 41.8 & $\begin{array}{l}\text { Hyper- } \\
\text { tension }\end{array}$ & 26,0 & 26,1 & 10.5 & 7 & 36 & 38 & Lopinavir & $\begin{array}{l}\text { Refractory } \\
\text { hypoxemia }\end{array}$ \\
\hline 5 & 33.6 & 30.8 & NA & 26,6 & 27,6 & 5.5 & 0 & 2 & 3 & NA & NA \\
\hline 6 & 39.4 & 31.3 & $\begin{array}{l}\text { Hashimoto } \\
\text { thyroiditis }\end{array}$ & 40,5 & POD 8 & 25 & NA & 4 & 5 & NA & NA \\
\hline 7 & $33.1 \dagger$ & 30.5 & NA & 23,5 & 23,5 & 1 & $\begin{array}{l}\text { Ongoing } \\
\text { pregnancy }\end{array}$ & 13 & 14 & Hydroxy & $\begin{array}{c}\text { latrogenic } \\
\text { transient } \\
\text { hepatitis }\end{array}$ \\
\hline 8 & 33.4 & 29.7 & NA & 28,2 & NA & NA & NA & NA & 3 & NA & NA \\
\hline 9 & 26.1 & 33.7 & Asthma & 36,0 & POD 1 & 24 & NA & 1 & 2 & NA & NA \\
\hline 10 & $42.1 \dagger$ & 29.3 & NA & 26,6 & 27,2 & 160 & 0 & 13 & 14 & NA & NA \\
\hline
\end{tabular}

*BMI, body mass index; GA, gestational age; Hydroxy, hydroxychloroquine; ID, patient identification; NA, not applicable; POD, postoperative day. †Patients who experienced acute respiratory distress syndrome before intubation.

(median gestational age at admission 27.9 weeks [IQR 27.2-28.8 weeks]) and 3 during early postpartum, $\leq 3$ days postpartum (Table 5). Among patients admitted to ICUs, 9 (90\%) required intubation after oxygen requirements reached $>5 \mathrm{~L} / \mathrm{min}$; the mean interval between increased oxygen need and intubation was 28.7 hours $(\mathrm{SD} \pm 49.9 \mathrm{~h})$. Six patients had acute respiratory distress syndrome (ARDS); 5 were treated with drug regimen, 3 with lopinavir, and 2 with hydroxychloroquine; 1 was placed in the prone position for ARDS. The average length of stay in the ICU was $9.1 \pm 5.7$ days.

Among women hospitalized in ICUs, 8 had cesarean deliveries because of rapid respiratory worsening: 5 before 32 weeks' gestation, 1 between 32 and 37 weeks' gestation, and 2 after 37 weeks' gestation
(Table 6). During their ICU stays, 3 women had complications: 1 had surgical site infection after cesarean delivery, 1 had iatrogenic pancreatitis attributed to lopinavir with Balthazar grade $C$, and 1 had iatrogenic and transient hepatitis attributed to hydroxychloroquine. No maternal deaths were noted. Among neonates delivered in this group, no acidosis or birthweight below the 10th percentile were noted. Five neonates were hospitalized in NICUs because of prematurity; 1 died at 7 days of age because of prematurity and bacterial sepsis (Tables 5, 6). Two women left the ICU with ongoing pregnancies.

\section{Discussion}

We report detailed experience managing 100 patients infected with SARS-CoV-2 in tertiary referral

Table 6. Obstetric and neonatal outcomes for pregnant women admitted to an intensive care unit with severe acute respiratory syndrome coronavirus 2, France*

\begin{tabular}{|c|c|c|c|c|c|c|c|c|c|c|}
\hline ID & $\begin{array}{c}\text { Prenatal } \\
\text { corticosteroid, } \\
\mathrm{GA}, \mathrm{wk}, \mathrm{d} \dagger\end{array}$ & $\begin{array}{c}\text { Prenatal } \\
\text { magnesium } \\
\text { sulfate, GA, } \\
\text { wk, d }+\end{array}$ & $\begin{array}{l}\text { Time from } \\
\text { diagnosis to } \\
\text { delivery, } \mathrm{d}\end{array}$ & $\begin{array}{l}\text { Mode of } \\
\text { delivery }\end{array}$ & $\begin{array}{c}\text { GA at } \\
\text { birth, wk, d }\end{array}$ & $\begin{array}{c}\text { Birthweight, g } \\
\text { (z-score) }\end{array}$ & $\begin{array}{l}\text { 5-min } \\
\text { Apgar } \\
\text { score } \\
\end{array}$ & $\begin{array}{l}\text { Umbilical } \\
\text { arterial pH }\end{array}$ & $\begin{array}{l}\text { Neonatal } \\
\text { intubation }\end{array}$ & $\mathrm{NICU}$ \\
\hline 1 & NA & 29 & 2 & Cesarean & 29 & $1,400(1.10)$ & 7 & 7.26 & $\mathrm{Y}$ & $\mathrm{Y}$ \\
\hline 2 & NA & NA & 8 & Cesarean & 39,1 & $3,290(0.06)$ & 10 & 7.21 & $\mathrm{~N}$ & $\mathrm{~N}$ \\
\hline 3 & 30,1 & $30+1$ & 11 & Cesarean & 30,2 & $1,500(0.75)$ & 8 & 7.25 & $\mathrm{Y}$ & $Y$ \\
\hline 4 & 26,4 & $26+4$ & 7 & Cesarean & 27,1 & $1,010(0.82)$ & 1 & 7.28 & $Y$ & $Y$ \\
\hline 5 & 26,1 & 26,4 & 7 & Cesarean & 27,6 & $890(-0.83)$ & 3 & 7.24 & Y & Y \\
\hline 6 & NA & NA & 1 & Cesarean & 40,6 & $3,570(0.18)$ & 3 & ND & $\mathrm{N}$ & $\mathrm{N}$ \\
\hline 7 & NA & 23,5 & $\begin{array}{l}\text { Ongoing } \\
\text { pregnancy }\end{array}$ & NA & NA & NA & NA & NA & NA & NA \\
\hline 8 & NA & 29,4 & $\begin{array}{l}\text { Ongoing } \\
\text { pregnancy }\end{array}$ & NA & NA & NA & NA & NA & NA & NA \\
\hline 9 & NA & NA & 1 & Cesarean & 36,1 & $2,940(0.49)$ & 10 & ND & $\mathrm{N}$ & $\mathrm{N}$ \\
\hline 10 & 26,6 & 27,1 & 3 & Cesarean & 27,2 & $1,065(1.12)$ & 10 & 7.27 & $\mathrm{Y}$ & $Y$ \\
\hline
\end{tabular}


obstetric units during the COVID-19 pandemic in France. Nearly half $(48 / 100)$ received close outpatient follow-up without any clinically significant events. The other 52 were hospitalized for monitoring or oxygen therapy, including $10(10 \%)$ who had critical infections and required hospitalization in ICUs. Lymphocytopenia, anemia, and need for oxygen flow $>5 \mathrm{~L} / \mathrm{min}$ at the time of diagnosis seem to be associated with a critical infection.

The management of pregnant women with SARS$\mathrm{CoV}-2$ is a particularly critical issue in tertiary referral obstetric units. In our cohort, $52 \%$ of patients were hospitalized and 9\% required invasive ventilation. The rate of severe and critical forms of COVID-19 reported among this group is higher than previously reported $(5,6,17-21)$, which can be explained by the general admissions to tertiary referral obstetric units. Tertiary obstetric units accept women with high-risk pregnancies and referrals from other maternity hospitals that lack technical platforms needed to support them. The 4 centers in our study offer adult and neonatal resuscitation, enabling optimal maternal management. Clinicians must weigh the continuation of the pregnancy against all the risks associated with premature birth that can lead to neonatal death. Having an adult ICU in the same facility as the maternity ward makes it possible to continue the pregnancy under conditions that seem acceptable.

Maternal and fetal clinical assessment at the time of diagnosis is essential for appropriate medical referral. Systematic laboratory tests, including hemoglobin level, blood count, hemostasis, and inflammatory evaluation, at the time of SARS-CoV-2 diagnosis in pregnant women could help to determine the level of risk for progression to an unfavorable form. Lymphocytopenia, increased C-reactive protein, and increased aPPT have an unfavorable prognostic value that could lead to an increased risk for severe COVID-19 forms in nonpregnant adults (22-25). Our study underlines the need to consider the lymphocyte count in the choice of medical approach; when counts are acceptable, outpatient management can be safely considered. However, close telemonitoring is required. In our cohort, $17 \%$ of patients followed up on an outpatient basis subsequently required hospitalization.

During early pregnancy ( $<32$ weeks' gestation), clinicians tried to continue the pregnancy because of the neonatal risks associated with premature birth. ICU hospitalization alone was not a criterion for delivery. However, analysis of our cohort data shows that in all pregnant women, a need for increasing oxygen flow rate to $>5 \mathrm{~L} / \mathrm{min}$ was a signal for invasive ventilation. All but 1 patient on invasive ventilation required cesarean delivery due to ventilatory instability. Antenatal corticosteroid therapy before 34 weeks' gestation and a neuroprotective course of magnesium sulfate before 32 weeks' gestation appears to be safe and appropriate when oxygen requirements increase. An average interval of $\geq 24$ hours between the increase in oxygen flow rate to $>5 \mathrm{~L} / \mathrm{min}$ and invasive ventilation enables the administration of $\geq 1$ of 2 recommended doses of corticosteroids and a complete course of magnesium sulfate.

Our study reports clinical and laboratory data at the time of diagnosis used to identify prognostic factors associated with an adverse outcome in pregnant women infected with SARS-CoV-2. Our findings can help clinicians around the world combat the pandemic.

Our study has several limitations. First, although we wanted to identify prognostic factors associated with adverse outcomes, our sample size of patients admitted to the ICU was too small to perform a robust multivariate analysis; our results are purely descriptive and not predictive. Second, our study used clinical and laboratory data only at the time of diagnosis, and we did not evaluate the effect of subsequent laboratory and clinical features. Finally, our study was retrospective and had missing data values.

Among our cohort, preterm births ( $<37$ weeks' gestation) accounted for $39 \%$ of all deliveries and the cesarean delivery rate was $48 \%$. However, the preterm birth and cesarean delivery rates we report could be lower once all the women with SARS-CoV-2 infections have given birth and full information becomes available.

Specific information on pregnant women receiving care for COVID-19 is still lacking, and literature from China reports low infection rates in this population. Tertiary referral obstetric units with a maternal ICU play a major role in the management of symptomatic pregnant women. In addition to maternal respiratory symptoms, neonatal conditions related to spontaneous or induced prematurity in relation to SARS-CoV-2 infection must be considered. In our study, careful clinical and laboratory evaluation at the time of diagnosis enabled safe outpatient monitoring for almost half of the pregnant women. Further investigations are required to assess the true risks associated with SARS-CoV-2 infection during pregnancy.

\section{About the Author}

Dr. Vivanti is a senior lecturer in obstetrics and gynecology at Antoine Béclère Hospital, University Paris Saclay, Clamart, France. His research interests include fetal medicine and surgery, high risk pregnancy, genetics, and neurodevelopment. 


\section{References}

1. Rasmussen SA, Smulian JC, Lednicky JA, Wen TS, Jamieson DJ. Coronavirus disease 2019 (COVID-19) and pregnancy: what obstetricians need to know. Am J Obstet Gynecol. 2020;222:415-26. https:/ / doi.org/10.1016/ j.ajog.2020.02.017

2. Breslin N, Baptiste C, Gyamfi-Bannerman C, Miller R, Martinez R, Bernstein K, et al. Coronavirus disease 2019 infection among asymptomatic and symptomatic pregnant women: two weeks of confirmed presentations to an affiliated pair of New York City hospitals. Am J Obstet Gynecol MFM. 2020;2:100118. https://doi.org/10.1016/ j.ajogmf.2020.100118

3. Zaigham M, Andersson O. Maternal and perinatal outcomes with COVID-19: A systematic review of 108 pregnancies. Acta Obstet Gynecol Scand. 2020;99:823-829. https://doi.org/10.1111/aogs.13867

4. Ferrazzi EM, Frigerio L, Cetin I, Vergani P, Spinillo A, Prefumo F, et al. COVID-19 Obstetrics Task Force, Lombardy, Italy: executive management summary and short report of outcome. Int J Gynaecol Obstet. 2020;149:377-8. https://doi.org/10.1002/ijgo.13162

5. Liu Y, Chen H, Tang K, Guo Y. Clinical manifestations and outcome of SARS-CoV-2 infection during pregnancy. J Infect. 2020 Mar 4 [Epub ahead of print]. https:/ / doi.org/10.1016/ j.jinf.2020.02.028

6. Chen H, Guo J, Wang C, Luo F, Yu X, Zhang W, et al. Clinical characteristics and intrauterine vertical transmission potential of COVID-19 infection in nine pregnant women: a retrospective review of medical records. Lancet. 2020; 395:809-15. https://doi.org/10.1016/S0140-6736(20)30360-3

7. Yu N, Li W, Kang Q, Xiong Z, Wang S, Lin X, et al. Clinical features and obstetric and neonatal outcomes of pregnant patients with COVID-19 in Wuhan, China: a retrospective, single-centre, descriptive study. Lancet Infect Dis. 2020; 20:559-64. https:/ / doi.org/10.1016/S1473-3099(20)30176-6

8. Vlachodimitropoulou Koumoutsea E, Vivanti AJ, Shehata N, Benachi A, Le Gouez A, Desconclois C, et al. COVID19 and acute coagulopathy in pregnancy. J Thromb Haemost. 2020. 2020 Apr 17 [Epub ahead of print]. https:/ / doi.org/ $10.1111 /$ jth.14856

9. Dong L, Tian J, He S, Zhu C, Wang J, Liu C, et al. Possible vertical transmission of SARS-CoV-2 from an infected mother to her newborn. JAMA. 2020;323:1846-48. https://doi.org/10.1001/jama.2020.4621

10. Della Gatta AN, Rizzo R, Pilu G, Simonazzi G. Coronavirus disease 2019 during pregnancy: a systematic review of reported cases. Am J Obstet Gynecol. 2020;223:36-41. https://doi.org/10.1016/j.ajog.2020.04.013

11. Corman VM, Landt O, Kaiser M, Molenkamp R, Meijer A, Chu, DK, et al. Detection of 2019 novel coronavirus (2019nCoV) by real-time RT-PCR. Euro Surveil. 2020;25:2000045. https://doi.org/10.2807/1560-7917.ES.2020.25.3.2000045

12. Zhang W, Du R-H, Li B, Zheng XS, Yang XL, Hu B, et al. Molecular and serological investigation of 2019-nCoV infected patients: implication of multiple shedding routes. Emerg Microbes Infect. 2020;9:386-9. https:/ / doi.org/1 $0.1080 / 22221751.2020 .1729071$

13. Wang W, Xu Y, Gao R, Lu R, Han K, Wu G, et al. Detection of SARS-CoV-2 in different types of clinical specimens. JAMA. 2020 Mar 11 [Epub ahead of print]. https:// doi.org/10.1001/ jama.2020.3786

14. Ai T, Yang Z, Hou H, Zhan C, Chen C, Lv W, et al. Correlation of chest CT and RT-PCR testing in coronavirus disease 2019 (COVID-19) in China: a report of 1014 cases. Radiology. 2020 Feb 26 [Epub ahead of print]. https://doi.org/10.1148/radiol.2020200642

15. US Centers for Disease Control and Prevention. Coronavirus disease 2019 (COVID-19) [cited 2020 Apr 29]. https:/ / www. cdc.gov/coronavirus/2019-ncov/index.html

16. US Centers for Disease Control and Prevention. Considerations for inpatient obstetric healthcare settings [cited 2020 Apr 29]. https:/ / www.cdc.gov/ coronavirus/2019-ncov/hcp/inpatient-obstetric-healthcareguidance.html

17. Di Mascio D, Khalil A, Saccone G, Rizzo G, Buca D, Liberati $\mathrm{M}$, et al. Outcome of coronavirus spectrum infections (SARS, MERS, COVID 1 -19) during pregnancy: a systematic review and meta-analysis. Am J Obstet Gynecol MFM. 2020 Mar 25 [Epub ahead of print]. https:/ / doi.org/10.1016/ j.ajogmf.2020.100107

18. Ferrazzi E, Frigerio L, Savasi V, Vergani P, Prefumo F, Barresi S, et al. Vaginal delivery in SARS-CoV-2-infected pregnant women in Northern Italy: a retrospective analysis. BJOG. 2020 Apr 27 [Epub ahead of print]. https://doi.org/10.1111/1471-0528.16278

19. Schwartz DA. An analysis of 38 pregnant women with COVID-19, their newborn infants, and maternal-fetal transmission of SARS-CoV-2: maternal coronavirus infections and pregnancy outcomes. Arch Pathol Lab Med. 2020 Mar 17 [Epub ahead of print]. https:/ / doi.org/10.5858/ arpa.2020-0901-SA

20. Wang S-S, Zhou X, Lin X-G, Liu Y-Y, Wu J-L, Mwamaka Sharifu L, et al. Experience of clinical management for pregnant women and newborns with novel coronavirus pneumonia in Tongji Hospital, China. Curr Med Sci. 2020;40:285-289. https://doi.org/10.1007/s11596-0202174-4

21. Yan J, Guo J, Fan C, Juan J, Yu X, Li J, et al. Coronavirus disease 2019 in pregnant women: a report based on 116 cases. Am J Obstet Gynecol. 2020;223:111.e1-14 https://doi.org/10.1016/j.ajog.2020.04.014

22. Henry BM, de Oliveira MHS, Benoit S, Plebani M, Lippi G. Hematologic, biochemical and immune biomarker abnormalities associated with severe illness and mortality in coronavirus disease 2019 (COVID-19): a meta-analysis. Clin Chem Lab Med. 2020;58:1021-8. https:/ / doi.org/10.1515/ cclm-2020-0369

23. Lippi G, Plebani M, Henry BM. Thrombocytopenia is associated with severe coronavirus disease 2019 (COVID-19) infections: a meta-analysis. Clin Chim Acta. 2020;506:145-8. https://doi.org/10.1016/j.cca.2020.03.022

24. Liu Y, Yang Y, Zhang C, Huang F, Wang F, Yuan J, et al. Clinical and biochemical indexes from 2019-nCoV infected patients linked to viral loads and lung injury. Sci China Life Sci. 2020;63:364-74. https:/ / doi.org/10.1007/ s11427-020-1643-8

25. Ruan Q, Yang K, Wang W, Jiang L, Song J. Clinical predictors of mortality due to COVID-19 based on an analysis of data of 150 patients from Wuhan, China. Intensive Care Med. 2020;46:846-848. https:/ / doi.org/ $10.1007 /$ s00134-020-05991-x

Address for correspondence: Alexandre J. Vivanti, Service de Gynécologie-Obstétrique, Hôpital A. Béclère, GHU Paris Saclay, APHP, 157 rue de la Porte de Trivaux, 92140 Clamart, France; email: alexandre.vivanti@aphp.fr 